\title{
Staged Sinus Floor Elevation Using Novel Low-Crystalline Carbonate Apatite Granules: Prospective Results after 3-Year Functional Loading
}

\author{
Yoichiro Ogino $1, *\left(\mathbb{D}\right.$, Yasunori Ayukawa ${ }^{1,2}$, Noriko Tachikawa $^{3}$, Masahiro Shimogishi ${ }^{3}$, Youji Miyamoto ${ }^{4}$, \\ Keiko Kudoh ${ }^{4} \oplus$, Naoyuki Fukuda ${ }^{4}{ }^{\oplus}$, Kunio Ishikawa ${ }^{5}$ and Kiyoshi Koyano ${ }^{6}$ \\ 1 Section of Fixed Prosthodontics, Division of Oral Rehabilitation, Faculty of Dental Science, Kyushu University, \\ Fukuoka 812-8582, Japan; ayukawa@dent.kyushu-u.ac.jp \\ 2 Section of Implant and Rehabilitative Dentistry, Division of Oral Rehabilitation, Faculty of Dental Science, \\ Kyushu University, Fukuoka 812-8582, Japan \\ 3 Department of Oral Implantology and Regenerative Dental Medicine, Tokyo Medical and Dental University, \\ Tokyo 113-8510, Japan; ntachikawa.impl@tmd.ac.jp (N.T.); shimogishi.irm@tmd.ac.jp (M.S.) \\ 4 Department of Oral Surgery, Institute of Biomedical Sciences, Tokushima University Graduate School, \\ Tokushima 770-8504, Japan; miyamoto@tokushima-u.ac.jp (Y.M.); kkudoh@tokushima-u.ac.jp (K.K.); \\ naoyukifukuda@tokushima-u.ac.jp (N.F.) \\ 5 Department of Biomaterials, Faculty of Dental Sciences, Kyushu University, Fukuoka 812-8582, Japan; \\ ishikawa@dent.kyushu-u.ac.jp \\ 6 Division of Advanced Dental Devices and Therapeutics, Faculty of Dental Science, Kyushu University, \\ Fukuoka 812-8582, Japan; koyano@dent.kyushu-u.ac.jp \\ check for \\ * Correspondence: ogino@dent.kyushu-u.ac.jp; Tel.: +81-92-642-6371
}

Citation: Ogino, Y.; Ayukawa, Y.; Tachikawa, N.; Shimogishi, M.; Miyamoto, Y.; Kudoh, K.; Fukuda, N.; Ishikawa, K.; Koyano, K. Staged Sinus Floor Elevation Using Novel Low-Crystalline Carbonate Apatite Granules: Prospective Results after 3-Year Functional Loading. Materials 2021, 14, 5760. https://doi.org/ $10.3390 /$ ma14195760

Academic Editor: Takahiro Kanno

Received: 19 August 2021

Accepted: 27 September 2021

Published: 2 October 2021

Publisher's Note: MDPI stays neutral with regard to jurisdictional claims in published maps and institutional affiliations.

Copyright: (c) 2021 by the authors. Licensee MDPI, Basel, Switzerland. This article is an open access article distributed under the terms and conditions of the Creative Commons Attribution (CC BY) license (https:// creativecommons.org/licenses/by/ $4.0 /)$.

Abstract: The aim of this study was to evaluate clinical outcomes of staged sinus floor elevation (SFE) using novel low-crystalline carbonate apatite $\left(\mathrm{CO}_{3} \mathrm{Ap}\right)$ granules. Patients who needed SFE for implant placement were recruited into this clinical trial. A staged procedure (lateral window technique using $\mathrm{CO}_{3}$ Ap granules, followed by implant placement after $7 \pm 2$ months) was employed in 13 patients. Bone-height increase and insertion torque values (ITVs) were assessed along with histological evaluation. The survival and success rates of 3-year functioning implants were also evaluated. Mean of bone-height increase after SFE using $\mathrm{CO}_{3} \mathrm{Ap}$ granules was $7.2 \pm 2.5 \mathrm{~mm}$ and this increase allowed implant placement in all cases (17 implants). Mean of ITV was $25.1 \pm 13.2 \mathrm{Ncm}$ and primary stability was achieved successfully in all cases. Histological analyses revealed mature new bone formation $(36.8 \pm 17.3 \%)$ and residual $\mathrm{CO}_{3}$ Ap granules $(16.2 \pm 10.1 \%)$ in the compartment after SFE. The survival and success rates after 3 -year functional loading were $100 \%$ and no complications were found. These results clearly indicate the clinical usefulness of $\mathrm{CO}_{3} \mathrm{Ap}$ granules for SFE.

Keywords: low-crystalline carbonate apatite $\left(\mathrm{CO}_{3} \mathrm{Ap}\right)$; sinus floor elevation; functioning implants

\section{Introduction}

Sinus floor elevation (SFE) has been reported to be a predictable treatment modality for implant placement in atrophic maxilla [1,2]. The SFE procedure includes two main techniques: the transcrestal (or transalveolar) technique and the lateral window technique [3]. The transcrestal technique using an osteotome approach is generally a less invasive procedure, has easier surgical technique, fewer complications and shorter surgical time [3,4]. On the other hand, the lateral window technique requires more invasive intervention and more skilled techniques [3-6]. However, this technique can be performed under direct vision and can increase more vertical space compared to the transcrestal technique [3,4]. Although the proper selection of surgical techniques is required depending on the anatomical situation, especially the residual bone height (threshold height: 4-6 $\mathrm{mm}$ ) [4-6], both techniques were clinically reliable and predictable [7-9]. 
In SFE using the lateral window technique, various graft materials have been used and evaluated. Autogenous bone has been considered as the gold standard because of its osteoinductive and osteoconductive properties [10]. However, the disadvantages of autogenous bone are limited availability, postoperative morbidity and resorption [11-13]. As alternatives to autogenous bone, bone substitutes including allogenic bone, xenograft and alloplastic graft materials have been widely used and investigated [14-18]. In particular, alloplastic graft materials such as beta-tricalcium phosphate $(\beta-\mathrm{TCP})$ and hydroxyapatite (HAp) have been used for SFE due to their potential capacities such as unlimited availability, ease of use and being less invasive. However, it should be noted that no artificial graft materials were approved in Japan for their clinical use in load-bearing area including implant-related bone reconstruction, due to their poor osteoconductivity when compared to autograft.

Since autograft is the gold standard, attempts to imitate bone seem reasonable to fabricate alloplastic graft materials with greater function. One of the key differences between bone and current alloplastic graft materials is the composition. While the composition of bone is carbonate apatite $\left(\mathrm{CO}_{3} \mathrm{Ap}\right)$, which contains approximately $6-9$ mass $\%$ carbonate $[19,20], \mathrm{CO}_{3} \mathrm{Ap}$ decomposes during sintering procedures due to the presence of carbonate in apatite crystal. In contrast, HAp and $\beta$-TCP can be sintered and show osteoconductivity, leading their use as alloplastic graft materials. However, we succeeded in fabricating low-crystalline $\mathrm{CO}_{3} \mathrm{Ap}$ granules in an aqueous solution through a dissolutionprecipitation reaction using a precursor such as calcium carbonate [21,22]. Histological analysis and cell study revealed higher osteoconductivity of $\mathrm{CO}_{3} \mathrm{Ap}$ when compared with other alloplastic graft materials [23-25]. Based on simulated clinical trials using beagle dogs, the first clinical trials of $\mathrm{CO}_{3} \mathrm{Ap}$ granules were performed in three university hospitals for SFE [26,27].

The aim of this study was to evaluate the follow-up results of staged SFE using novel $\mathrm{CO}_{3} \mathrm{Ap}$ granules with respect to bone height increase, insertion torque values (ITVs), replacement of $\mathrm{CO}_{3} \mathrm{Ap}$ to a new bone, and survival and success rates of the implants after functional loading. The null hypothesis was that staged SFE using $\mathrm{CO}_{3} \mathrm{Ap}$ granules did not have clinical availability for implant placement and occlusal loading.

\section{Materials and Methods}

\subsection{Research Design and Ethical Approval}

At first, this study was planned and conducted as a multicenter, single-arm, clinical trial in three university dental hospitals (Kyushu University Hospital, Tokyo Medical and Dental University Hospital, and Tokushima University Hospital). This clinical trial was conducted from January, 2015 to May, 2017 in accordance with the Declaration of Helsinki. The institutional review board approved this study as a clinical trial (clinical trial No. GCAP-01, \#2014904). This clinical study was also registered as JPRN-UMIN000019281 in the University Hospital Medical Information Network in Japan as a clinical trial and the International Clinical Trials Registry Platform Search Portal of the World Health Organization. After the completion of this clinical trial, a subsequent study was planned and conducted as a prospective observational study. This observational study was approved by the institutional review board (\#29-299, D2017-029 and 2927) and was conducted according to Strengthening the reporting of observational studies in epidemiology (STROBE).

Prior to the conduction of this clinical trial, Pharmaceuticals and Medical Devices Agency (PMDA) in Tokyo, Japan advised us that at least 20 subjects would be necessary to assess the effect of $\mathrm{CO}_{3} \mathrm{Ap}$ granules on bone formation and the safety of $\mathrm{CO}_{3} \mathrm{AP}$ clinically. This clinical trial was planned to enroll at least 20 patients as subjects following PMDA's suggestions.

The patients who needed SFE for implant placement could be candidates for this clinical trial. The candidates who met the criteria were enrolled as the subjects (Table 1). 
Table 1. Inclusion and exclusion criteria.

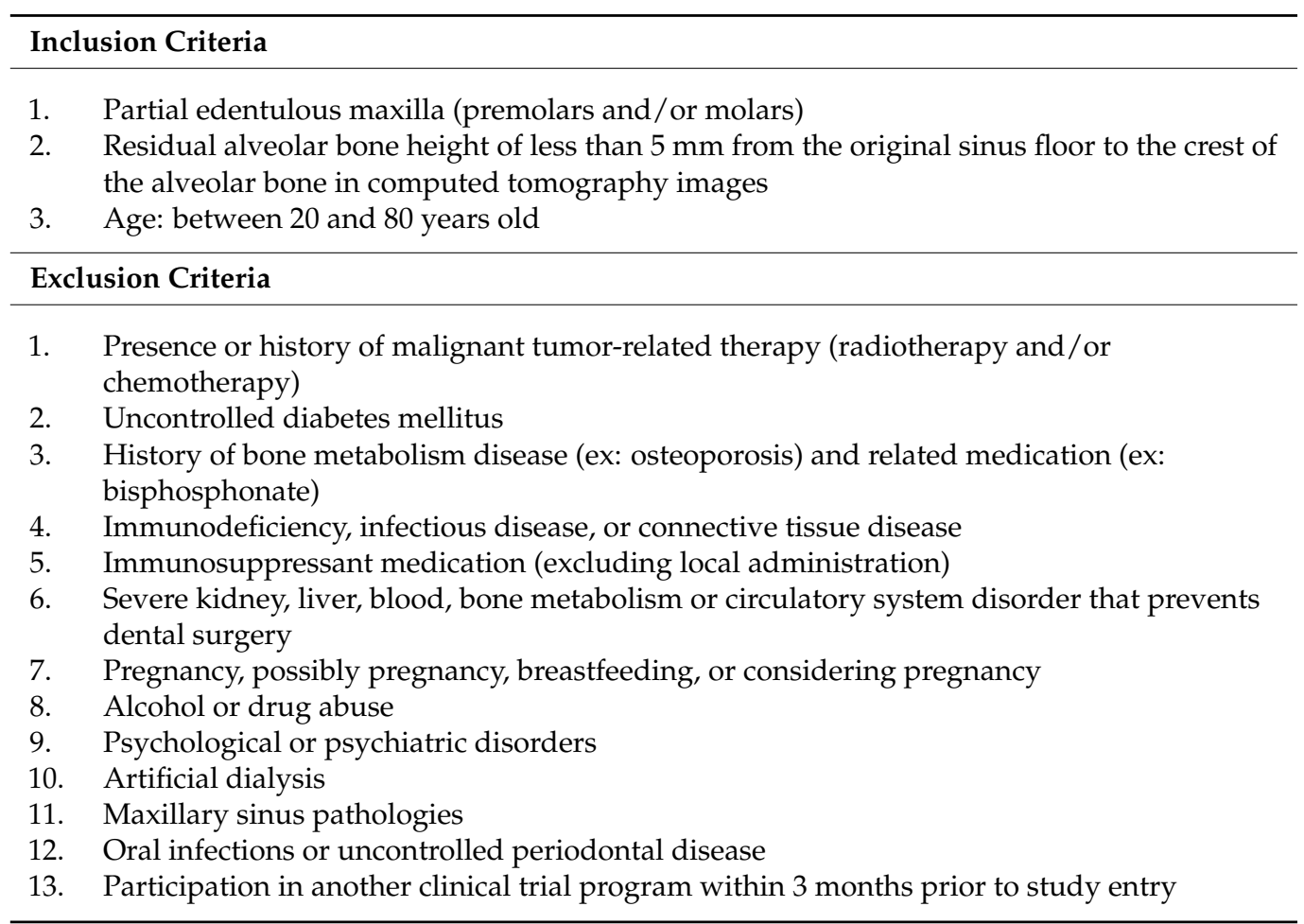

\subsection{Surgical Procedure for Sinus Floor Elevation (SFE) and Implant Placement}

In this study, the patients assigned to staged SFE (SFE using $\mathrm{CO}_{3} \mathrm{Ap}$ granules via lateral window technique followed by implant placement after healing of $7 \pm 2$ months) were evaluated and were followed up.

The patients had computed tomography (CT) examinations with diagnostic stents prior to SFE (pre-SFE CT image). SFE with the graft of $\mathrm{CO}_{3} \mathrm{Ap}$ granules (GC Cytrans Granules, GC, Tokyo, Japan) was conducted under local infiltration anesthesia. The particle size of $\mathrm{CO}_{3}$ Ap granules was in the range of $600-1000 \mu \mathrm{m}$. Briefly, the lateral wall of the sinus was exposed after the reflection of a full-thickness mucoperiosteum flap and a bony window was created. The Schneiderian membrane was separated carefully using sinus membrane elevators and the compartment was created by the sinus membrane elevation procedure. This compartment was filled with $\mathrm{CO}_{3} \mathrm{Ap}$ granules. The study protocol did not allow to use membrane to cover the lateral window. The first surgery was completed with the sutures (Figure 1).

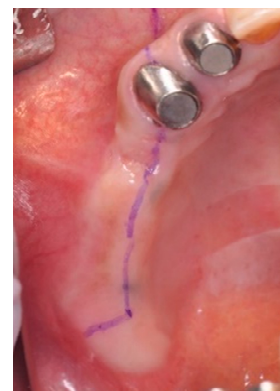

(a)

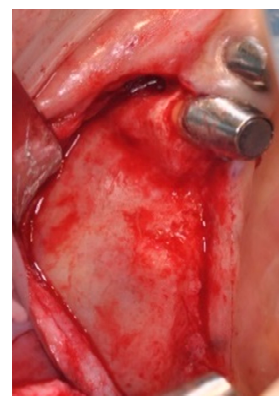

(b)

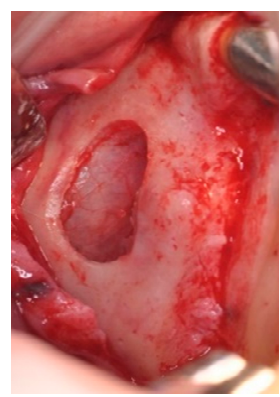

(c)

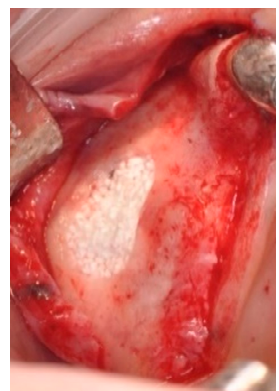

(d)

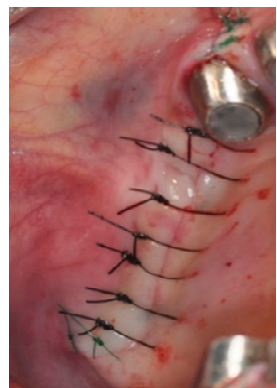

(e)

Figure 1. Sinus floor elevation (SFE) with lateral window technique: (a) Preoperative intraoral image; (b) Exposure of lateral sinus wall; (c) Sinus membrane elevation procedure from lateral sinus wall; (d) Graft of $\mathrm{CO}_{3} \mathrm{Ap}$ granules; (e) Completion of SFE with sutures. 
After a healing period of $7 \pm 2$ months $[13,15,16]$, a second CT examination with the same diagnostic stent was conducted to measure the bone height and to plan the implant placement (preimplantation CT image). Prior to implant placement, implant sites were prepared with a trephine bur (2.1 $\mathrm{mm}$ diameter) to obtain bone specimens for histological analysis. Implant placements were performed as manufacturers' instructions.

\subsection{Implant Restorative Procedure}

After $8 \pm 2$ months of healing period for osseointegration, a second surgery for uncovering the dental implant and connecting the abutment to the implant body was performed, and provisional restorations and definitive prostheses were fabricated as per the manufacturers' instructions. All of the patients were asked to attend prospective observational studies, including regular implant maintenance programs, after informed consent.

\subsection{Analyses of Outcomes}

\subsubsection{SFE Evaluation in a Clinical Trial}

This study was conducted as a first clinical trial, followed by a prospective observational study. The primary outcome of the clinical trial was the evaluation of ITVs $(\geq 10 \mathrm{Ncm})$ as biomechanical characteristics of newly formed bone. The secondary outcome was the result of bone biopsy. The newly formed bone was assessed histologically. The composition of the newly formed bone (mature bone, osteoid and residual $\mathrm{CO}_{3} \mathrm{Ap}$ granules) was also evaluated with bone specimen after Villanueva-Goldner staining by well-experienced pathologists. Image J software (1.52u, 2020, National Institutes of Health, Bethesda, MD, USA) was used for histomorphometric analysis. In addition, bone height increase was calculated using pre-SFE and preimplantation CT images (the difference in bone height between two images) by a well-experienced radiologist using the OsiriX medical imaging software program (version 7.5, Open-Source, OsiriX Medical Imaging Software, http: / / www.osirix-viewer.com, accessed on 22 November, 19 and 26 December, 2016). The images (frontal views) used for analyses were selected based on the position of the diagnostic stents to match the images. Both analyses were performed in a blinded manner.

\subsubsection{Clinical and Radiographic Evaluations after 3-Year Functional Loading}

Clinical and radiographic evaluations (panoramic radiography) were conducted at implant placement, at the delivery of final prosthesis and 3 years after the delivery. Implant survival rates and success rates based on criteria according to the previous studies $[9,28,29]$ were assessed as a 3-year evaluation. The success criteria were as follows:

- No detectable mobility on clinical examination;

- No pain or other subjective sensation from the implant;

- No recurrent peri-implant infection or sign of peri-implantitis;

- No continuous radiolucency in the peri-implant bone.

A time-sequence chart of the procedures was shown (Figure 2).

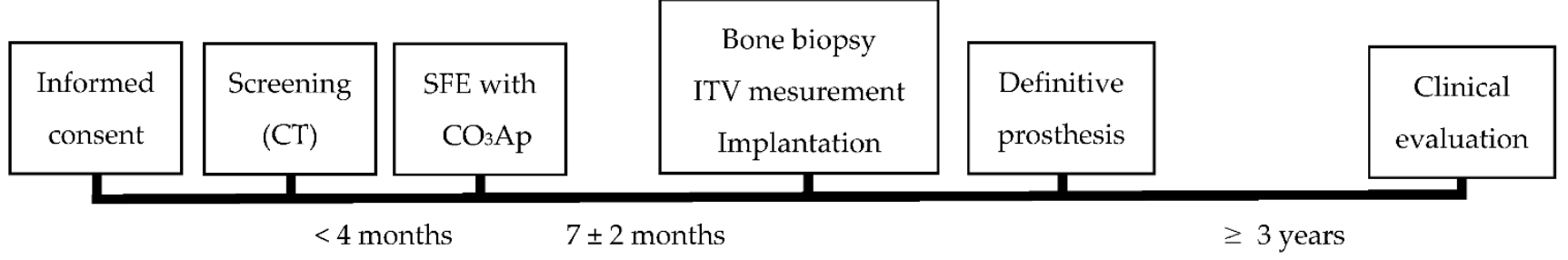

Figure 2. A time-sequence chart of the procedures. CT: computed tomography; SFE: sinus floor elevation; $\mathrm{CO}_{3} \mathrm{Ap}$ : carbonate apatite; ITV: insertion torque value. 


\section{Results}

\subsection{Patients}

In total, 22 patients enrolled and had SFE using $\mathrm{CO}_{3} \mathrm{Ap}$ granules. Eight of 22 patients had SFE for simultaneous implant placement and 14 patients were assigned to the staged SFE procedure. One patient who had staged SFE was excluded from the analysis because the complex of $\mathrm{CO}_{3} \mathrm{Ap}$ granules and autogenous bone was used as graft materials for SFE. As a result, 13 patients (four males and nine females, mean age: $61.0 \pm 11.7$ ) and 17 implants were included in this study. The detailed data are described in Table 2.

Table 2. Patient's profiles and the data of SFE and bone biopsy.

\begin{tabular}{|c|c|c|c|c|c|c|c|}
\hline \multirow{2}{*}{ Age and Gender } & \multirow{2}{*}{ Site } & \multirow{2}{*}{$\begin{array}{c}\text { Pre-SFE } \\
\text { Bone Height } \\
(\mathrm{mm})\end{array}$} & \multirow{2}{*}{$\begin{array}{c}\mathrm{CO}_{3} \mathrm{AP} \\
\text { Amount }\left(\mathrm{cm}^{3}\right)\end{array}$} & \multirow{2}{*}{$\begin{array}{c}\text { Pre-Implant } \\
\text { Placement Bone } \\
\text { Height }(\mathrm{mm})\end{array}$} & \multicolumn{3}{|c|}{ Histomorphometrical Analyses (\%) } \\
\hline & & & & & Mature Bone & Osteoid & $\mathrm{CO}_{3} \mathrm{AP}$ \\
\hline \multirow{2}{*}{ 71, Female } & 16 & 5.0 & \multirow[b]{2}{*}{1.2} & 8.8 & \multirow[b]{2}{*}{10.7} & \multirow[b]{2}{*}{0.7} & \multirow{2}{*}{23.1} \\
\hline & 17 & 3.8 & & 14.5 & & & \\
\hline 64, Male & 26 & 5.0 & 1.5 & 8.1 & 58.2 & 1.6 & 14.0 \\
\hline 69 , Female & 25 & 4.4 & 0.8 & 13.3 & 24.6 & 0.6 & 1.3 \\
\hline 43, Female & 26 & 5.0 & 0.7 & 13.3 & 23.1 & 1.5 & 34.8 \\
\hline 64, Female & 25 & 2.6 & 1.9 & 13.0 & 55.7 & 1.9 & 24.8 \\
\hline 77, Female & 27 & 3.6 & 1.0 & 7.5 & 47.5 & 1.4 & 9.2 \\
\hline 56, Male & 16 & 3.3 & 1.5 & 11.2 & 48.5 & 3.0 & 13.6 \\
\hline \multirow{2}{*}{67 , Female } & 25 & 5.0 & \multirow{2}{*}{1.4} & 9.0 & \multirow{2}{*}{35.7} & \multirow{2}{*}{2.4} & \multirow{2}{*}{4.8} \\
\hline & 26 & 2.0 & & 10.3 & & & \\
\hline 71, Male & 26 & 4.0 & 1.4 & 12.0 & 30.1 & 0.6 & 7.5 \\
\hline 60 , Female & 25 & 4.1 & 1.8 & 9.3 & 49.8 & 0.6 & 18.3 \\
\hline 37, Female & 15 & 3.6 & 0.4 & 12.7 & 24.6 & 3.6 & 12.7 \\
\hline 64, Male & 26 & 2.0 & 0.8 & 8.4 & 59.1 & 5.2 & 15.0 \\
\hline \multirow{3}{*}{ 50, Female } & 14 & 3.0 & & 8.9 & \multirow{3}{*}{11.1} & \multirow{3}{*}{3.4} & \multirow{3}{*}{31.6} \\
\hline & 15 & 1.4 & 2.5 & 9.8 & & & \\
\hline & 16 & 1.0 & & 11.1 & & & \\
\hline Mean \pm SD & & $3.5 \pm 1.3$ & $1.3 \pm 0.6$ & $10.7 \pm 2.1$ & $36.8 \pm 17.3$ & $\begin{array}{c}2.0 \pm \\
1.4\end{array}$ & $\begin{array}{c}16.2 \pm \\
10.1\end{array}$ \\
\hline
\end{tabular}

SFE: sinus floor elevation; $\mathrm{CO}_{3} \mathrm{Ap}$ : carbonate apatite; SD: standard deviation.

\subsection{The Results of Surgical Procedures}

During SFE, no perforation of the sinus membranes was detected. The CT images (frontal views) of pre-SFE and pre-implantation are shown in Figure 3. Table 2 also presents SFE sites and vertical bone heights measured using pre-SFE and pre-implantation CT images. The mean increase of bone height after SFE with $\mathrm{CO}_{3} \mathrm{Ap}$ graft was $7.1 \pm 2.4 \mathrm{~mm}$ (mean \pm standard deviation (SD)). They revealed that the $\mathrm{CO}_{3} \mathrm{Ap}$ graft could maintain the vertical height and the space between the elevated sinus membrane and sinus floor. The amounts of $\mathrm{CO}_{3} \mathrm{Ap}$ granules used for SFE are also presented in Table 2.

The implants were placed uneventfully in all cases. Detailed information regarding implants and ITVs, the primary outcome of this clinical trial, are described in Table 3. ITVs were not recorded in one patient with three implants. The mean ITV was $25.1 \pm 13.2 \mathrm{Ncm}$ $($ mean $\pm \mathrm{SD})$. All implants could acquire primary stability. 


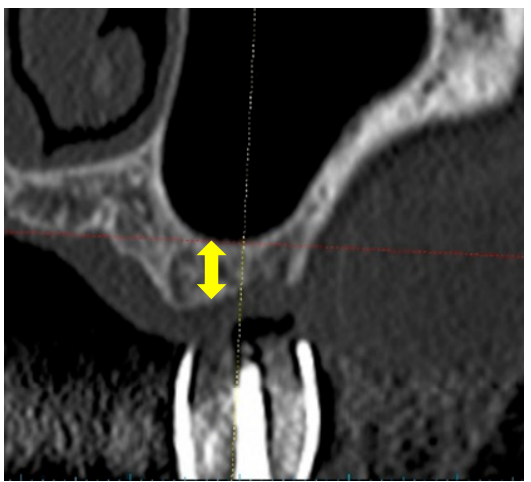

(a)

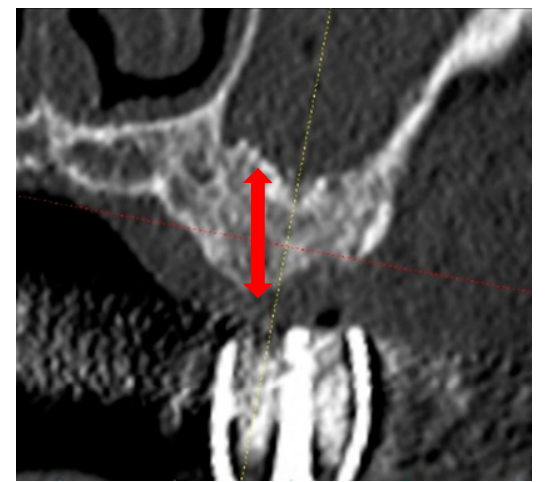

(b)

Figure 3. CT images of pre-SFE and pre-implantation. (a) Pre-SFE (frontal view), the yellow allow shows pre-vertical bone height; (b) Pre-implantation (frontal view), the red allow shows post-vertical bone height.

Table 3. Data on implant placement.

\begin{tabular}{|c|c|c|c|c|c|}
\hline \multirow{2}{*}{ Age and Gender } & \multirow{2}{*}{ Site } & \multirow{2}{*}{ ITV (Ncm) } & \multicolumn{3}{|c|}{ Implant } \\
\hline & & & Company & Diameter (mm) & Length (mm) \\
\hline 64, Male & 26 & 30 & SM & 4.8 & 8.0 \\
\hline \multirow{2}{*}{ 71, Female } & 16 & 14 & SM & 4.1 & 8.0 \\
\hline & 17 & 15 & SM & 4.1 & 10.0 \\
\hline 69 , Female & 25 & 15 & NB & 4.0 & 10.0 \\
\hline 43, Female & 26 & 22 & DP & 4.5 & 9.0 \\
\hline 64, Female & 25 & 14 & NB & 3.8 & 10.0 \\
\hline 77, Female & 27 & 20 & GC & 4.4 & 8.0 \\
\hline 56, Male & 16 & 49 & SM & 4.1 & 8.0 \\
\hline \multirow{2}{*}{67 , Female } & 25 & 12 & NB & 4.3 & 8.5 \\
\hline & 26 & 13 & NB & 4.3 & 11.5 \\
\hline 71, Male & 26 & 50 & GC & 4.4 & 10.0 \\
\hline 60, Female & 25 & 36 & SM & 4.1 & 8.0 \\
\hline 37, Female & 15 & 37 & GC & 3.8 & 8.0 \\
\hline 64, Male & 26 & 25 & SM & 4.8 & 8.0 \\
\hline \multirow{3}{*}{ 50, Female } & 14 & NR & GC & 3.8 & 10.0 \\
\hline & 15 & NR & GC & 3.8 & 10.0 \\
\hline & 16 & NR & GC & 3.8 & 8.0 \\
\hline
\end{tabular}

ITV: insertion torque value; NR: not recorded; SM: Straumann AG, Basel, Switzerland; NB: Nobel Biocare AB, Göteborg, Sweden; DP: Dentsply Implants, Mölndal, Sweden; GC: GC Corporation, Tokyo, Japan.

A histological specimen (Villanueva-Goldner staining) is shown in Figure 4. In this staining, mature bone was stained in green, and osteoid was stained in red. New bone formation and residual $\mathrm{CO}_{3} \mathrm{Ap}$ granules were observed. Residual $\mathrm{CO}_{3} \mathrm{Ap}$ granules were surrounded by newly formed bone and osteoid was observed around new bone and $\mathrm{CO}_{3} \mathrm{Ap}$ granules. The specimens were used to calculate the ratio of bone area to total area. The composition of mature bone, osteoid and residual $\mathrm{CO}_{3} \mathrm{Ap}$ granules was calculated for histomorphometrical examinations. The mean ratios of mature bone, osteoid and residual $\mathrm{CO}_{3}$ Ap granules were $37.6 \pm 16.9,2.4 \pm 1.3$ and $15.4 \pm 10.1 \%$ (mean $\pm \mathrm{SD}$ ), respectively (Table 2). 


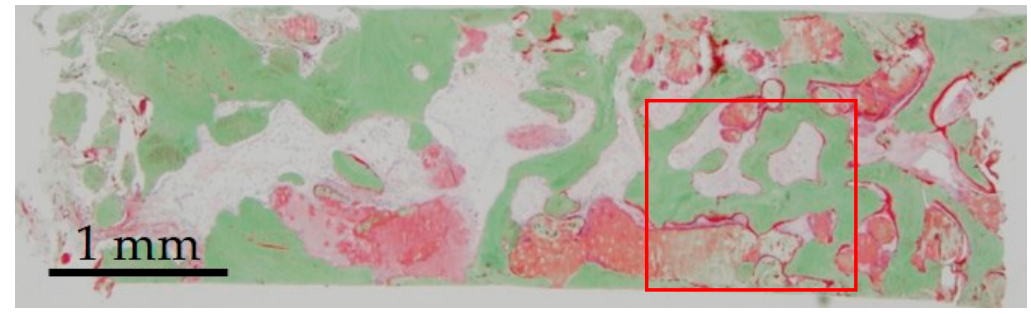

(a)

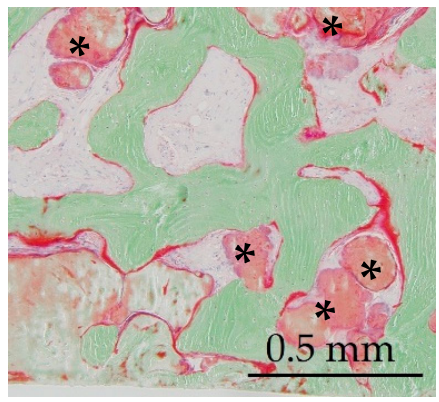

(b)

Figure 4. Histological analysis of newly formed bone after SFE (Villanueva-Goldner staining). Mature bone is stained green and osteoid is stained red: (a) Low magnification; (b) Higher magnification of red square in (a). *: residual $\mathrm{CO}_{3} \mathrm{Ap}$ granules.

\subsection{Clinical Outcomes}

After implant placement, all implant-related surgeries (second operations: connection of healing abutments) and prosthetic procedures were completed successfully. Functional loading with definitive prostheses was possible in all cases. All implants in 12 patients have functioned for 3 years uneventfully. Unfortunately, definitive prosthesis in one patient did not achieve 3-year function, although the implant was loaded for more than 3 years with a provisional restoration. Implant survival rate was 100\%. Implant success rate after 3-year functional loading was assessed with clinical findings and panoramic radiographic images based on the success criteria (Figure 5). All implants were stable and showed no mobility. No patients complained of pain or peri-implant soft tissue inflammation. In addition, panoramic radiography analyses showed no continuous radiolucency in the peri-implant bone. These findings revealed that implant success rate was also $100 \%$.

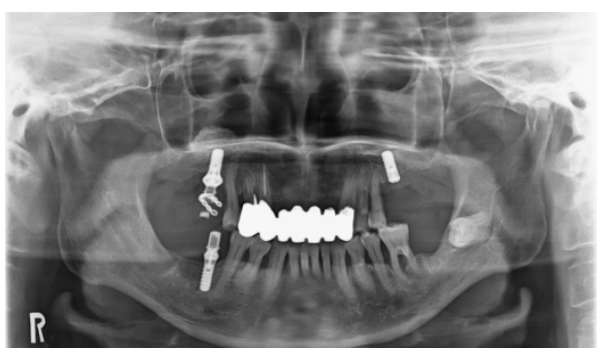

(a)

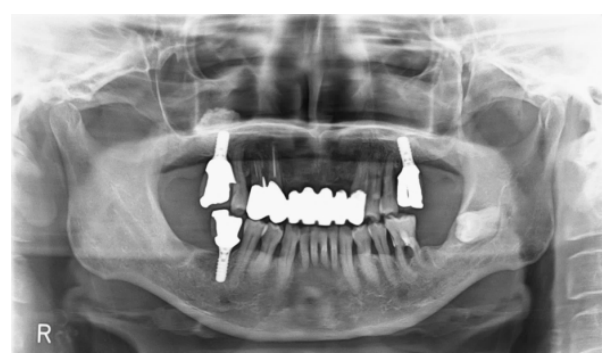

(b)

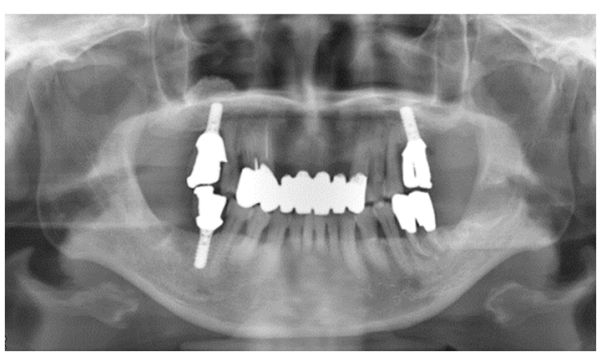

(c)

Figure 5. Panoramic radiographic images. SFE and implant at maxillary left molar site. (a) At implant placement; (b) At the delivery of final restoration; (c) At 3-year follow-up.

\section{Discussion}

Previous studies showed that SFE using the lateral window technique could achieve favorable clinical outcomes $[1,2,7,9]$. The lateral window technique was recommended in cases with less residual bone height $(\leq 5-6 \mathrm{~mm})[4,9]$, and delayed implant placement was recommended in the cases with residual bone height $<4 \mathrm{~mm}[9,30,31]$. In these cases, the lateral window technique using a graft material would be useful to maintain the space between the sinus membrane and floor, although a previous report suggested the effectiveness of SFE without any graft materials in space maintenance [32]. The most important factor in implant placement with SFE is to acquire the primary stability. To stabilize implants, sufficient bone height or volume, including pre-existing bone and newly formed bone, and mineralization, would be required. Previous studies revealed that SFE applying the lateral window technique with a graft material was a safe and predictable surgical procedure, especially in severe (less pre-existing bone height) cases [32-34]. This first clinical trial was conducted to evaluate the clinical availability of $\mathrm{CO}_{3} \mathrm{Ap}$, which is a component of natural bone, as a graft material in SFE [30,31], and this study aimed to 
report the result after 3-year functional loading. The findings of this subsequent study have shown the clinical availability of $\mathrm{CO}_{3} \mathrm{Ap}$ granules for SFE and implant treatment.

This clinical trial was planned to measure the vertical height at implant site (indicated by a diagnostic stent in CT image) to assess the result of SFE. The mean value of vertical bone height prior to SFE was $3.5 \pm 1.3 \mathrm{~mm}$. All sites were less than $6 \mathrm{~mm}$ and 10 sites were less than $4 \mathrm{~mm}$, which were recommended to receive delayed implant placement $[9,30,31]$. $\mathrm{CT}$ images revealed that $\mathrm{CO}_{3} \mathrm{Ap}$ granules worked effectively as a graft material in SFE and as materials for space maintenance and new bone formation $(7.1 \pm 2.4 \mathrm{~mm})$. However, future CT evaluation of three-dimensional mineralization after SFE (vertical and horizontal dimension) would be favorable. The histological analyses showed new bone formation and bone mineralization. The formation of osteoid around residual $\mathrm{CO}_{3} \mathrm{Ap}$ granules, which was similar to newly formed bone, suggested the capacity for bone formation by $\mathrm{CO}_{3} \mathrm{Ap}$ granules. ITVs revealed the primary stability in all cases. In addition, all implants and prostheses functioned uneventfully after 3-year functional loading (survival and success rates: $100 \%$ ) and these results suggested the availability of $\mathrm{CO}_{3} \mathrm{Ap}$ granules as a graft material in SFE and delayed implant placement.

Previous studies have reported the results of SFE with various graft materials. They suggested that the type of graft materials were not assumed to be associated with clinical outcomes [11,14]. We would like to focus attention on the characteristics of $\mathrm{CO}_{3} \mathrm{Ap}$ granules. The apatite in human bone is $\mathrm{CO}_{3} \mathrm{Ap}$, not hydroxyapatite (HAp) $[19,20]$. In comparison with $\mathrm{HAp}$ in vitro, $\mathrm{CO}_{3} \mathrm{Ap}$ is resorbed by osteoclasts [35] and enhances osteoblastic activities [25]. $\mathrm{CO}_{3} \mathrm{Ap}$ fabricated by the dissolution-precipitation reaction showed more bone replacement compared to Bio-Oss [23]. The evaluation of bone formation using three commercially available bone substitutes with different composition $\left(\mathrm{CO}_{3} \mathrm{Ap}, \mathrm{HAp}\right.$ and $\beta$-tricalcium phosphate) revealed that $\mathrm{CO}_{3} \mathrm{Ap}$ demonstrated the highest level of new bone formation and suggested that similar composition of bone could contribute to bone formation [36]. In addition, SFE using $\mathrm{CO}_{3} \mathrm{Ap}$ granules in simultaneous and delayed implant placements has been shown to achieve bone-height increase and successful osseointegration [26,27]. These studies revealed the availability of $\mathrm{CO}_{3} \mathrm{Ap}$ granules as a graft material in SFE and implant placement experimentally and clinically. This study could demonstrate the clinical effectiveness of $\mathrm{CO}_{3} \mathrm{Ap}$ granules in SFE after 3-year functional loading, which is necessary for implant restoration. We believe that this study encourages the clinical application of $\mathrm{CO}_{3} \mathrm{Ap}$ granules in SFE and implant placement.

Prior to conclusion of this study, it is required to mention its limitations. Firstly, the clinical assessment was limited to small sample size. This study was conducted as an observational study following a first clinical trial [27]. As mentioned above, we needed to enroll 22 patients to conduct a clinical trial without any control groups, and 14 of them were assigned to staged SFE. Although studies to evaluate the availability of $\mathrm{CO}_{3} \mathrm{Ap}$ granules as a graft material will be reported in the near future, this study could provide important data on the clinical availability of $\mathrm{CO}_{3}$ Ap granules after functional loading. Secondly, detailed analyses such as the change in peri-implant bone level were not conducted. The change in peri-implant bone level has been known to be affected by multiple factors [37-40]. The design of this study was SFE, in which bone resorption might occur at coronal (preexisting bone) and apical (augmented bone) sites. The aim of this study was to evaluate the clinical availability of $\mathrm{CO}_{3} \mathrm{Ap}$ granules and the prognosis of the implants (the survival and success rates of implants in newly formed bone by $\mathrm{CO}_{3} \mathrm{Ap}$ granules) was reported. These success criteria, including radiographic evaluations, were widely adopted as the evaluation of implant prognosis after functional loading [9,28,29], although other success criteria have been widely used [41]. This study did not evaluate peri-implant bone level using standardized X-ray images and it was difficult to evaluate the change of bone level precisely. The previous studies also reported survival and success rates of implants placed after SFE $[1,2,4,11,13,15]$. No remarkable bone resorption around implants was observed radiographically and all implants were defined as successful implants clinically. Whereas this study suggested the clinical availability of $\mathrm{CO}_{3} \mathrm{Ap}$ granules used in SFE, future studies 
will be required to evaluate the effect of $\mathrm{CO}_{3} \mathrm{Ap}$ granules on new bone formation and temporal changes of newly formed bone around implants, not only in SFE but also in bone augmentation around the implants. Finally, temporal change of $\mathrm{CO}_{3} \mathrm{Ap}$ granules could not be analyzed in detail. The histological analyses at implant placement showed that the new bone formation and the residual $\mathrm{CO}_{3} \mathrm{Ap}$ granules depended on each subject. The statistical correlation analysis among the ratio of new bone formation, residual $\mathrm{CO}_{3} \mathrm{Ap}$ granules and numerical data within the small sample size identified no significant correlation (data not shown), which suggested that contributing factors for bone formation in SFE using $\mathrm{CO}_{3}$ Ap granules still remain unknown. In addition, detailed bone formation after implant placement could not be assessed. A well-designed future study should be considered to estimate the temporal changes of bone quality and quantity formed by $\mathrm{CO}_{3} \mathrm{Ap}$ granules.

\section{Conclusions}

This study revealed that $\mathrm{CO}_{3} \mathrm{Ap}$ granules formed new bone after SFE, and the newly formed bone supported implants successfully after 3-year functional loading, suggesting the clinical availability of $\mathrm{CO}_{3}$ Ap granules in implant rehabilitation. Further studies are required to validate the factors related to new bone formation clinically, and to compare the bone formation between $\mathrm{CO}_{3} \mathrm{Ap}$ granules and other graft materials.

Author Contributions: Conceptualization, Y.M., K.I. and K.K. (Kiyoshi Koyano); methodology, Y.M., K.I. and K.K. (Kiyoshi Koyano); software, Y.O.; validation, Y.O., Y.A., K.K. (Keiko Kudoh) and M.S.; formal analysis, Y.O., Y.A., M.S., K.K. (Keiko Kudoh) and N.F.; investigation, Y.O., N.T., M.S., K.K. (Keiko Kudoh) and N.F.; resources, Y.M. and K.I.; data curation, Y.O. and Y.A.; writing-original draft preparation, Y.O. and Y.A.; writing—review and editing, N.T., Y.M., K.I. and K.K. (Kiyoshi Koyano); visualization, Y.O. and Y.A.; supervision, N.T., Y.M., K.I. and K.K. (Kiyoshi Koyano); project administration, Y.O., Y.A., M.S. and K.K. (Keiko Kudoh); funding acquisition, Y.M., K.I. and K.K. (Kiyoshi Koyano). All authors have read and agreed to the published version of the manuscript.

Funding: This research (clinical trial) was funded by GC Corporation (Tokyo, Japan). However, they did not play a role in the conduct of this clinical trial and data collection.

Institutional Review Board Statement: The study was conducted according to the guidelines of the Declaration of Helsinki. The institutional review board approved this subsequent study as a clinical trial (clinical trial No. GCAP-01, \#2014904, date of approval: 5 June 2015) and as a follow-up observational study (\#29-299, date of approval: 21 September 2017; D2017-029, date of approval: 5 September 2017; and 2927, date of approval: 24 July 2017).

Informed Consent Statement: Informed consent was obtained from all subjects involved in the study.

Data Availability Statement: All the data is available within the manuscript.

Acknowledgments: The authors would like to thank Kazunori Yoshiura for his help with CT image analyses and Naozumi Ishimaru for his help with the preparation of histological specimens.

Conflicts of Interest: As we mention above, this research (clinical trial) was funded by GC Corporation (Tokyo, Japan). One of the authors (K.K. (Kiyoshi Koyano)) belongs to the Division of Advanced Dental Devices and Therapeutics, Faculty of Dental Science, Kyushu University. This division is endowed by GC Corporation, Tokyo, Japan. However, GC Corporation had no specific roles in this study. The other authors declare no conflict of interest.

\section{References}

1. Aghaloo, T.L.; Misch, C.; Lin, G.-H.; Iacono, V.J.; Wang, H.-L. Bone Augmentation of the Edentulous Maxilla for Implant Placement: A Systematic Review. Int. J. Oral Maxillofac. Implant. 2017, 31, s19-s30. [CrossRef]

2. Raghoebar, G.M.; Onclin, P.; Boven, G.C.; Vissink, A.; Meijer, H.J.A. Long-term effectiveness of maxillary sinus floor augmentation: A systematic review and meta-analysis. J. Clin. Periodontol. 2019, 46, 307-318. [CrossRef]

3. Danesh-Sani, S.A.; Loomer, P.M.; Wallace, S.S. A comprehensive clinical review of maxillary sinus floor elevation: Anatomy, techniques, biomaterials and complications. Br. J. Oral Maxillofac. Surg. 2016, 54, 724-730. [CrossRef] [PubMed]

4. Al-Dajani, M. Recent Trends in Sinus Lift Surgery and Their Clinical Implications. Clin. Implant. Dent. Relat. Res. 2016, 18, 204-212. [CrossRef] [PubMed] 
5. Kawakami, S.; Botticelli, D.; Nakajima, Y.; Sakuma, S.; Baba, S. Anatomical analyses for maxillary sinus floor augmentation with a lateral approach: A cone beam computed tomography study. Ann. Anat. 2019, 226, 29-34. [CrossRef] [PubMed]

6. Testori, T.; Tavelli, L.; Yu, S.-H.; Scaini, R.; Darnahal, A.; Wallace, S.S.; Wang, H.-L. Maxillary Sinus Elevation Difficulty Score with Lateral Wall Technique. Int. J. Oral Maxillofac. Implant. 2020, 35, 631-638. [CrossRef]

7. Farina, R.; Franceschetti, G.; Travaglini, D.; Consolo, U.; Minenna, L.; Schincaglia, G.P.; Riccardi, O.; Bandieri, A.; Maietti, E.; Trombelli, L. Morbidity following transcrestal and lateral sinus floor elevation: A randomized trial. J. Clin. Periodontol. 2018, 45, 1128-1139. [CrossRef]

8. Crespi, R.; Toti, P.; Covani, U.; Crespi, G.; Menchini-Fabris, G.-B. Clinical and Radiographic Evaluation of Modified Transalveolar Two-Step Osteotome-Mediated Localized Maxillary Sinus Elevation: A Retrospective Computed Tomography Study with a 3-Year Follow-up. Int. J. Oral Maxillofac. Implant. 2021, 36, 553-560. [CrossRef] [PubMed]

9. Zhou, Y.; Shi, Y.; Si, M.; Wu, M.; Xie, Z. The comparative evaluation of transcrestal and lateral sinus floor elevation in sites with residual bone height $\leq 6 \mathrm{~mm}$ : A two-year prospective randomized study. Clin. Oral Implant. Res. 2021, 32, 180-191. [CrossRef] [PubMed]

10. Precheur, H.V. Bone Graft Materials. Dent. Clin. N. Am. 2007, 51, 729-746. [CrossRef]

11. Nkenke, E.; Stelzle, F. Clinical outcomes of sinus floor augmentation for implant placement using autogenous bone or bone substitutes: A systematic review. Clin. Oral Implant. Res. 2009, 20 (Suppl. S4), 124-133. [CrossRef]

12. Klijn, R.J.; Beucken, J.J.J.P.V.D.; Bronkhorst, E.; Berge, S.J.; Meijer, G.J.; Jansen, J.A. Predictive value of ridge dimensions on autologous bone graft resorption in staged maxillary sinus augmentation surgery using Cone-Beam CT. Clin. Oral Implant. Res. 2011, 23, 409-415. [CrossRef] [PubMed]

13. Tosta, M.; Cortes, A.R.G.; Corrêa, L.; Pinto, D.D.S.; Tumenas, I.; Katchburian, E. Histologic and histomorphometric evaluation of a synthetic bone substitute for maxillary sinus grafting in humans. Clin. Oral Implant. Res. 2011, 24, 866-870. [CrossRef] [PubMed]

14. Chavda, S.; Levin, L. Human Studies of Vertical and Horizontal Alveolar Ridge Augmentation Comparing Different Types of Bone Graft Materials: A Systematic Review. J. Oral Implant. 2018, 44, 74-84. [CrossRef] [PubMed]

15. Galindo-Moreno, P.; de Buitrago, J.G.; Padial-Molina, M.; Fernández-Barbero, J.E.; Ata-Ali, J.; O'valle, F. Histopathological comparison of healing after maxillary sinus augmentation using xenograft mixed with autogenous bone versus allograft mixed with autogenous bone. Clin. Oral Implant. Res. 2018, 29, 192-201. [CrossRef]

16. Kolerman, R.; Nissan, J.; Rahmanov, M.; Calvo-Guirado, J.L.; Green, N.T.; Tal, H. Sinus augmentation analysis of the gradient of graft consolidation: A split-mouth histomorphometric study. Clin. Oral Investig. 2019, 23, 3397-3406. [CrossRef]

17. Chaushu, L.; Silva, E.R.; Balan, V.F.; Chaushu, G.; Xavier, S.P. Sinus augmentation-Autograft vs. fresh frozen allograft: Bone density dynamics and implant stability. J. Stomatol. Oral Maxillofac. Surg. in press. 2020. [CrossRef]

18. Al-Moraissi, E.; Alkhutari, A.; Abotaleb, B.; Altairi, N.; Del Fabbro, M. Do osteoconductive bone substitutes result in similar bone regeneration for maxillary sinus augmentation when compared to osteogenic and osteoinductive bone grafts? A systematic review and frequentist network meta-analysis. Int. J. Oral Maxillofac. Surg. 2020, 49, 107-120. [CrossRef]

19. Zapanta-Legeros, R. Effect of Carbonate on the Lattice Parameters of Apatite. Nature 1965, 206, 403-404. [CrossRef]

20. Legeros, R.Z.; Trautz, O.R.; Legeros, J.P.; Klein, E.; Shirra, W.P. Apatite Crystallites: Effects of Carbonate on Morphology. Science 1967, 155, 1409-1411. [CrossRef]

21. Ishikawa, K. Bone Substitute Fabrication Based on Dissolution-Precipitation Reactions. Materials 2010, 3, 1138-1155. [CrossRef]

22. Ishikawa, K.; Matsuya, S.; Lin, X.; Lei, Z.; Yuasa, T.; Miyamoto, Y. Fabrication of low crystalline B-type carbonate apatite block from low crystalline calcite block. J. Ceram. Soc. Jpn. 2010, 118, 341-344. [CrossRef]

23. Fujisawa, K.; Akita, K.; Fukuda, N.; Kamada, K.; Kudoh, T.; Ohe, G.; Mano, T.; Tsuru, K.; Ishikawa, K.; Miyamoto, Y. Compositional and histological comparison of carbonate apatite fabricated by dissolution-precipitation reaction and Bio-Oss ${ }^{\circledR}$. J. Mater. Sci. Mater. Electron. 2018, 29, 121. [CrossRef]

24. Mano, T.; Akita, K.; Fukuda, N.; Kamada, K.; Kurio, N.; Ishikawa, K.; Miyamoto, Y. Histological comparison of three apatitic bone substitutes with different carbonate contents in alveolar bone defects in a beagle mandible with simultaneous implant installation. J. Biomed. Mater. Res. Part B Appl. Biomater. 2020, 108, 1450-1459. [CrossRef]

25. Nagai, H.; Kobayashi-Fujioka, M.; Fujisawa, K.; Ohe, G.; Takamaru, N.; Hara, K.; Uchida, D.; Tamatani, T.; Ishikawa, K.; Miyamoto, Y. Effects of low crystalline carbonate apatite on proliferation and osteoblastic differentiation of human bone marrow cells. J. Mater. Sci. Mater. Electron. 2015, 26, 1-8. [CrossRef] [PubMed]

26. Kudoh, K.; Fukuda, N.; Kasugai, S.; Tachikawa, N.; Koyano, K.; Matsushita, Y.; Ogino, Y.; Ishikawa, K.; Miyamoto, Y. Maxillary Sinus Floor Augmentation Using Low-Crystalline Carbonate Apatite Granules With Simultaneous Implant Installation: First-inHuman Clinical Trial. J. Oral Maxillofac. Surg. 2019, 77, 985.e1-985.e11. [CrossRef]

27. Nakagawa, T.; Kudoh, K.; Fukuda, N.; Kasugai, S.; Tachikawa, N.; Koyano, K.; Matsushita, Y.; Sasaki, M.; Ishikawa, K.; Miyamoto, Y. Application of low-crystalline carbonate apatite granules in 2-stage sinus floor augmentation: A prospective clinical trial and histomorphometric evaluation. J. Periodontal Implant. Sci. 2019, 49, 382-396. [CrossRef] [PubMed]

28. Buser, D.; Mericske-Stern, R.; Bernard, J.P.P.; Behneke, A.; Behneke, N.; Hirt, H.P.; Belser, U.C.; Lang, N.P. Long-term evaluation of non-submerged ITI implants. Part 1: 8-year life table analysis of a prospective multi-center study with 2359 implants. Clin. Oral Implant. Res. 1997, 8, 161-172. [CrossRef] 
29. Cochran, D.L.; Buser, D.; Bruggenkate, C.M.T.; Weingart, D.; Taylor, T.M.; Bernard, J.-P.; Peters, F.; Simpson, J.P. The use of reduced healing times on ITI®implants with a sandblasted and acid-etched (SLA) surface: Early results from clinical trials on ITI SLA implants. Clin. Oral Implant. Res. 2002, 13, 144-153. [CrossRef] [PubMed]

30. Krennmair, G.; Krainhöfner, M.; Schmid-Schwap, M.; Piehslinger, E. Maxillary sinus lift for single implant-supported restorations: A clinical study. Int. J. Oral Maxillofac. Implant. 2007, 22, 351-358.

31. Romero-Millán, J.; Martorell-Calatayud, L.; Peñarrocha, M.; García-Mira, B. Indirect Osteotome Maxillary Sinus Floor Elevation: An Update. J. Oral Implant. 2012, 38, 799-804. [CrossRef]

32. Ting, M.; Rice, J.G.; Braid, S.M.; Lee, C.Y.S.; Suzuki, J.B. Maxillary Sinus Augmentation for Dental Implant Rehabilitation of the Edentulous Ridge: A comprehensive overview of systematic reviews. Implant. Dent. 2017, 26, 438-464. [CrossRef]

33. Silva, L.D.; de Lima, V.; Faverani, L.; de Mendonça, M.; Okamoto, R.; Pellizzer, E. Maxillary sinus lift surgery—with or without graft material? A systematic review. Int. J. Oral Maxillofac. Surg. 2016, 45, 1570-1576. [CrossRef]

34. Starch-Jensen, T.; Jensen, J.D. Maxillary Sinus Floor Augmentation: A Review of Selected Treatment Modalities. J. Oral Maxillofac. Res. 2017, 8, e1. [CrossRef]

35. Doi, Y.; Shibutani, T.; Moriwaki, Y.; Kajimoto, T.; Iwayama, Y. Sintered carbonate apatites as bioresorbable bone substitutes. J. Biomed. Mater. Res. Off. J. Soc. Biomater. Jpn. Soc. Biomater. Aust. Soc. Biomater. 1998, 39, 603-610. [CrossRef]

36. Ishikawa, K.; Miyamoto, Y.; Tsuchiya, A.; Hayashi, K.; Tsuru, K.; Ohe, G. Physical and Histological Comparison of Hydroxyapatite, Carbonate Apatite, and $\beta$-Tricalcium Phosphate Bone Substitutes. Materials 2018, 11, 1993. [CrossRef]

37. Klinge, B. Peri-implant marginal bone loss: An academic controversy or a clinical challenge? Eur. J. Oral Implant. 2012, 5, S13-S19.

38. Firme, C.T.; Vettore, M.V.; Melo, M.; Vidigal, G.M., Jr. Peri-implant Bone Loss Around Single and Multiple Prostheses: Systematic Review and Meta-Analysis. Int. J. Oral Maxillofac. Implant. 2014, 29, 79-87. [CrossRef] [PubMed]

39. De Bruyn, H.; Christiaens, V.; Doornewaard, R.; Jacobsson, M.; Cosyn, J.; Jacquet, W.; Vervaeke, S. Implant surface roughness and patient factors on long-term peri-implant bone loss. Periodontol 2000 2017, 73, 218-227. [CrossRef] [PubMed]

40. Ogino, Y.; Matsushita, Y.; Sasaki, M.; Ayukawa, Y.; Koyano, K. A 3-Year Prospective Study on Radiographic Marginal Bone Evaluation Around Platform-Shifting Implants with Internal Conical Connections. Int. J. Oral Maxillofac. Implant. 2021, 36, 574-580. [CrossRef] [PubMed]

41. Albrektsson, T.; Zarb, G.; Worthington, P.; Eriksson, A.R. The long-term efficacy of currently used dental implants: A review and proposed criteria of success. Int. J. Oral Maxillofac. Implant. 1986, 1, 11-25. 